\title{
La Universidad Latinoamericana como recuperación y futuro
}

\author{
Jorge Mario Rodríguez-Martínez ${ }^{1}$ \\ Universidad de San Carlos de Guatemala (Guatemala) \\ Grupo de investigación HISULA \\ jorgerodriguez.guat@gmail.com
}

Recepción: 19/09/2013

Evaluación: 18/10/2013

Aceptación: 13/12/2013

Artículo de Reflexión

DOI: http: / / dx.doi.org / 10.9757/Rhela.22 / 01

RESUMEN

Este trabajo argumenta que las universidades latinoamericanas contemporáneas deben asumir algunas de las tareas de regeneración ética y política de sociedades, cuya viabilidad está en cuestión debido a la corrupción, la violencia y la exclusión que las ha afectado desde su mismo origen. Las universidades latinoamericanas deben encontrar los propios caminos de superación de esta crisis sistémica por medio de la reflexión sobre los propios contextos socioculturales de las sociedades que las albergan. Esto implica buscar de manera crítica las vetas positivas de los contextos culturales que han generado nuestras sociedades y cuestionar los modelos filosóficos políticos que, originándose en otros contextos sociohistóricos, se quieren imponer de manera mecánica en nuestras sociedades. La filosofía política del expresidente guatemalteco Juan José Arévalo, un profesional de la pedagogía y la filosofía que gobernó a Guatemala de 1945 a 1950 muestra que esto es posible.

Palabras clave: Revista Historia de la Educación Latinoamericana, universidad, desigualdad, ética, cultura.

1 Doctor en filosofía (Ph. D) York University. Licenciado en filosofía, Universidad de San Carlos de Guatemala (USAC., Maestro en filosofía en Ohio University, Catedrático de la Escuela de Posgrado en Derecho de la USAC, Director del Instituto de Investigaciones de la Escuela de Posgrado en Derecho del Centro Universitario de Occidente de la USAC. Integrante del grupo de investigación HISULA, adscrit a la Universidad Pedagógica y Tecnológica de Colombia, Este manuscrito se articula al proyecto Reformas y movimientos universitarios en Colombia SGI 1295, desarrollado por el grupo Ilustración en América Colonial, ILAC y financiado por la Dirección de Investigaciones de la Universidad Pedagógica y Tecnológica de Colombia 
Latin American Universities: Between Tradition and Future

ABSTRACT

This essay argues that contemporary Latin American universities need to assume the task of helping to reconstruct the ethical and political background of societies whose viability is in question due to the corruption, violence, and exclusion that have affected them throughout history. Part of this mission consists in reflecting upon their societies' socio-cultural backgrounds, in order not only to recognize their positive aspects, but also to question those political philosophical models that, responding to other contexts, have been mechanically imposed in the region. This task is illustrated with a reflection upon the political philosophy developed by Guatemalan expresident Juan José Arévalo, an educator and philosopher who governed Guatemala from 1945 to 1950.

Keywords: Journal: History of Latin American Education, university, inequality, ethics, culture

\author{
A Universidade Latino-americana \\ como resgate e futuro
}

RESUMO

Este trabalho parte do argumento de que as universidades latino-americanas contemporâneas devem assumir algumas das tarefas de regeneração ética e política da sociedade, cuja viabilidade está em questão devido à corrupção, à violência e à exclusão que a têm afetado desde sua própria origem. As universidades latino-americanas devem encontrar os próprios caminhos de superação desta crise sistêmica através da reflexão sobre os próprios contextos socioculturais das sociedades em que estão inseridas. Isto implica buscar, de maneira crítica, as possibilidades dos contextos culturais que geraram nossas sociedades e questionar os modelos filosófico-políticos que, originando-se em outros contextos sócio-históricos, querem se impor de maneira mecânica em sociedades. A filosofia política do expresidente Juan José Arévalo, um profissional da pedagogia e da filosofia que governou a Guatemala de 1945 a 1950, mostra que isto é possível.

Palavras-chave: Revista História da Educação Latino-americana, universidade, desigualdade, ética, cultura.

\section{INTRODUCCIÓN}

Este trabajo plantea una serie de reflexiones sobre algunas de las tareas éticas, políticas y culturales, cuyo desarrollo corresponde a las universidades latinoamericanas. Sostengo la tesis de que estas instituciones pueden constituir espacios de reflexión para establecer modalidades alternativas, pero orgánicas, de legitimación para nuestras sociedades. Esta misión asume el desarrollo y actualización conceptual de los legados conceptuales vinculados al origen de tales sociedades. Las universidades latinoamericanas deben contribuir a un proceso consciente de recuperación selectiva de los potenciales normativos de las tradiciones que han formado a sus sociedades. Dicha tarea le permite a la universidad construir valladares ético-políticos para oponerse a los componentes homogeneizadores y alienantes de una globalización que ya no puede ser entendida únicamente en clave neoliberal. 
La primera parte de este ensayo plantea la tesis de que la injusticia estructural que afecta a nuestra región posee una raigambre fundamentalmente ética. La dimensión ética de dicha injusticia, sin embargo, no es capturada por los discursos que han devenido hegemónicos en las últimas décadas; desde esta perspectiva, se empieza a argumentar en favor de una recuperación crítica de nuestras tradiciones intelectuales. En la segunda, se sostiene que la vida intelectual latinoamericana, especialmente en las universidades, comienza con una crítica de la inhumanidad de la conquista y con un intento de reconocimiento del Otro. En esa tarea, ya se perfilan elementos culturales que exigen nuevas formas de ejercicio político, aún en nuestro tiempo. Finalmente, la tercera sección concluye esta reflexión describiendo con cierta precisión las tareas concretas que competen a nuestros centros de enseñanza superior. Consideraciones breves respecto al sentido de comunidad y la obra de Juan José Arévalo cierran esta sección.

\section{La raíz ética de nuestra injusticia estructural}

Se puede partir de una premisa básica: la raíz fundamental de los problemas políticos latinoamericanos -la crónica crisis de legitimidad de sus ordenamientos políticos- radica en estructuras sociales excluyentes. Aún un intelectual que sostiene una visión positiva de la historia política de la región, como Paul W. Drake, piensa que el dilema fundamental de las sociedades latinoamericanas siempre ha sido la reconciliación de una igualdad formal con una desigualdad profunda en la que, frecuentemente, la "distribución de poder social" ha socavado "la eficacia de las instituciones democráticas". 2

Dicha desigualdad, fundamentalmente expresada en el desencuentro entre la realidad y legitimidad, posee una profundidad y ubicuidad notable, lo cual denota su naturaleza ética. Los diferentes significados que se le puedan atribuir a la injusticia estructural pueden coincidir en que dicha injusticia está instalada en las interacciones sociales de las sociedades latinoamericanas. En efecto, todo contacto social -en tanto contacto comunicativo mediado por discursos- supone un contacto entre seres humanos concretos. Nuestra sensibilidad ética, por lo tanto, se encuentra integrada en el mundo social.

2 Paul W. Drake, Between Tyranny and Anarchy: A History of Democracy in Latin America, 1800-2006, (Stanford: Stanford University Press, 2009), 2. 
La reflexión del párrafo precedente no ha pasado inadvertida por los filósofos latinoamericanos. Luis Villoro, por ejemplo, ha insistido en que la filosofía moral latinoamericana surge de la experiencia de la injusticia como sufrimiento gratuito y sin sentido. ${ }^{3}$ Esta experiencia no puede desligarse de la política. En este sentido, es de destacar lo que dice Guillermo Hoyos, cuando, al examinar el cariz ético de la filosofía latinoamericana, se acerca a la experiencia de la injusticia para explicar que: "[1]a sensibilidad moral antes que fundamentar la moral busca expresiones para denunciar su negación apelando al sentimiento de humanidad y de equidad que subyace al sentido de lo público". ${ }^{4}$ Desde mi perspectiva, dicho sentido inmediato de la injusticia se fundamenta en una noción de lo ético que enfatiza la propia autolimitación o como lo ha planteado Emanuel Levinas, ${ }^{5}$ con el reconocimiento de una responsabilidad frente al Otro que no puede ser reducida al propio interés. Lo ético supone un reconocimiento de una responsabilidad asimétrica, es decir, una responsabilidad que no se agota en la reciprocidad. La ética supone el sacrificio, una conciencia de que estamos sujetos normativamente al Otro.

Al asumir esta dirección, se destaca la racionalidad de una determinada filosofía política crítica cuyo objeto es el sujeto autorreferencial y autosuficiente que ha sido promovido por la familia de doctrinas liberales. Si el reconocimiento del Otro permea las interacciones básicas de una sociedad, los enfoques liberales se enfrentan a una experiencia -la de la injusticia, la del sufrimiento del Otro- que cuestiona su propio paradigma. Lo ético, en este sentido, convoca a los agentes morales a la transformación de las estructuras morales que provocan tal experiencia.

Estas reflexiones encajan con la creciente conciencia de la vinculación entre injusticia social e individualidad. La filósofa norteamericana Iris Marion Young, por ejemplo, reconoce que las "estructuras sociales existen solo en la acción e interacción de las personas; existen no como estados de cosas, sino como procesos". ${ }^{6}$ La responsabilidad política supone el reconocimiento de la propia participación en procesos sociales que generan resultados injustos. ${ }^{7}$ Así, Young reconoce que la injusticia estructural está vinculada al hecho de

\footnotetext{
Luis Villoro, Tres retos de la sociedad por venir: Justicia, Democracia, Pluralidad (México: D.F.: Siglo XXI, 2009$), 14$. Guillermo Hoyos Vásquez, "Filosofía latinoamericana significa uso ético de la razón práctica”, Isegoría 19 (1998): 91. Emanuel Levinas, Totalidad e infinito: Ensayo sobre la exterioridad (Salamanca: Sígueme, 2006).

Iris Marion Young. Political Responsibility and Structural Injustice, (Kansas: Departamento de Filosofía, Universidad de Kansas, 2001), 5 .

7 Ibid., 15.
} 
que aceptamos las reglas y convenciones de las sociedades e instituciones en las que ejercitamos nuestras acciones. ${ }^{8}$ Aquí puede verse la relevancia de los contextos culturales, dado que estos ofrecen patrones sociales que pueden neutralizar la praxis ética.

Esto motiva consideraciones relativas a la violencia. Enrique Desmond Arias y Daniel M. Goldstein argumentan que si la violencia es una medida del fallo de una democracia, las democracias formales de América Latina serían profundamente no democráticas. ${ }^{9}$ Estos autores sostienen que la violencia ha sido instrumental para mantener instituciones y las políticas que los gobiernos neoliberales establecieron en la región. ${ }^{10}$ Esta última aseveración puede extenderse más allá de los gobiernos neoliberales para abarcar un trayecto más largo de nuestra historia.

Así, el discurso democrático se ve apuntalado por la violencia que lo desmiente. La realidad de desigualdad, por otro lado, nunca se asume: se justifica, se palia, se mantiene, y, en ese momento, la violencia se instala en las estructuras sociales y alcanza sus cumbres en el crimen y la corrupción. Al aceptar que la violencia ha desempeñado un rol para mantener una institucionalidad determinada, se asume que esta es precaria. Y iqué precariedad es más fuerte que el hecho de que la sociedad latinoamericana haya nacido con una fractura normativa inmensa, la negación de la vida del indígena, que se ha ido transformando a lo largo del tiempo en una realidad de exclusión? ¿Puede negarse que esta violencia estructural se haya ido ramificando en las múltiples violencias que acosan las sociedades latinoamericanas?

El mismo hecho de que la violencia sea instrumental al sistema apunta a prácticas culturales y discursivas que deben ser cuestionadas desde su raíz. Lo dicho nos lleva, por un lado, a examinar de manera crítica las vetas positivas $y$, desde luego, negativas de los contextos culturales que han generado nuestras sociedades; $y$, por el otro, a cuestionar los modelos filosóficos políticos que, al originarse en otros contextos sociohistóricos, se quieren imponer de manera mecánica en nuestras sociedades. Aquí se esboza una de las misiones básicas de las universidades latinoamericanas, estas

\footnotetext{
8 Ibid., 12.

9 Enrique Desmond Arias y Daniel M. Goldstein, Violent Democracies of Latin America, (Durham, North Carolina: Duke University Press, 2010), 2.

10 Ibid., 5.
} 
deben ayudar a encontrar los propios caminos de superación de esta crisis sistémica por medio de la reflexión sobre los propios contextos culturales de sus sociedades. Las universidades latinoamericanas, en este sentido, ofrecen posibilidades de crítica para una lógica cultural que ha ido sometiendo al mundo a los dictados de la razón capitalista.

Los esquemas discursivos que responden a otras lógicas sociohistóricas a menudono capturan la experiencia dela injusticia; el sujetoliberal seencuentra condicionado por múltiples asunciones relativas a la preeminencia del propio interés. Recordemos cómo el propio John Rawls supone en su versión del contrato que los participantes en este son mutuamente desinteresados. ${ }^{11}$ Dicho desinterés e individualismo colisionan con el dato de una conciencia o sensibilidad moral cuya interpelación originaria se da en un contexto social en el cual campea el sufrimiento gratuito.

Para comprender la relevancia de la historia cultural es necesario reflexionar sobre la noción misma de cultura. Y se puede empezar criticando algunos de los enfoques que se han ensayado para comprender nuestras crisis. Un ejemplo lo proveen los parámetros teóricos asumidos por el Programa de las Naciones Unidas para el Desarrollo (PNUD) expuestas en Cultural Liberty in Today's Diverse World, documento en el cual se desarrollan un grupo de ideas cuya promoción y defensa ha corrido a cargo del filósofo hindúamericano Amartya Sen y del canadiense Will Kymlicka. ${ }^{12}$

Las ideas de Kymlicka y Sen parten de la validez del marco liberal: mientras Sen ensancha la idea de libertad para incluir una diversidad de proyectos de vida, Kymlicka tiene en mente la posibilidad de reconciliar los derechos individuales liberales con los colectivos. Lamentablemente, la fusión de ambos enfoques planteada por medio de la idea de libertad cultural desarrollada por el PNUD no captura la complejidad de las relaciones conflictivas que operan dentro de nuestras sociedades. Es difícil, desde luego, negar el valor de una noción de libertad que aboga para que la gente desarrolle las capacidades necesarias "para llevar las vidas que ellos valoran y tienen razones para

11 John Rawls, A Theory of Justice. Edición revisada, (Cambridge, Massachusetts: Harvard University Press, 1999), 12.

12 United Nations Development Programme, Democracy in Latin America: Towards a Citizen's Democracy (New York: United Nations Development Programme, 2004). La idea original de elaborar estos reportes de desarrollo humano ha sido inspirada en las ideas de desarrollo propuestas por Amartya Sen. Puede verse cómo tal empeño ya refleja los paradigmas liberales adoptados por la ONU. Cabe preguntarse entonces si el modelo de derechos defendido por las Naciones Unidas toma en cuenta la diversidad cultural que existe en todo el mundo. 
valorar" ${ }^{13}$ Nunca nos opondríamos al momento de verdad que visualiza el "desarrollo humano" como "el proceso de ensanchar las opciones para que las personas puedan hacer y ser lo que ellos valoran en la vida". ${ }^{14}$

Pero ¿qué sucede cuando todas estas caracterizaciones sirven para defender una visión de la libertad cultural que se reduce a la posibilidad de elegir nuestra identidad? La tesis de que las culturas son merecedoras de protección debido al hecho de que ellas realzan las posibilidades de elección individual, simplemente, no encaja con la fenomenología moral que nos recuerdan Hoyos y Villoro. Menos aún, la cultura no es un "estilo de vida" que se escoge de manera libre, las culturas oprimidas no se almacenan cual trajes intercambiables en el ropero de las identidades.

En este contexto, las ideas del recientemente fallecido filósofo ecuatorianomexicano Bolívar Echeverría podrían cumplir un papel fundamental. Echeverría destacaba la idea de que el mestizaje desempeña un papel esencial en toda caracterización de la cultura. Gracias a las ideas de este autor, el barroco latinoamericano ya no es visto tan solo como una reacción estética al mundo clásico renacentista sino como un proceso de mestizaje cultural constituido por las culturas indígenas y la cultura hispana. La cultura se relaciona con el "cultivo de lo que la sociedad humana tiene de polis o agrupación de individuos concretos" que se lanza a la empresa de realizar sus "necesidades vitales", ${ }^{15}$ de un modo creativo y crítico. Esta perspectiva no encaja con una visión reificada de la identidad sino más bien con un proceso continuo de mestizaje. ${ }^{16}$

Ahora bien, ¿se pueden localizar en las tradiciones culturales de nuestra región elementos culturales que puedan ser movilizados para abordar nuestros problemas? Aquí se sitúa el argumento fundamental de este trabajo: la recuperación del pasado no es una tarea inútil, en ella se concretiza una región importante del sentido y la realización de una comunidad determinada. Como empresa sociopolítica, dicha tarea recae en gran medida en nuestras universidades. La apropiación crítica de estos elementos proyecta un nuevo sentido de vida en el cual hay una genuina interculturalidad, algo que va más allá de estrategias, imaginarios sociales y esencialismos estratégicos.

\footnotetext{
13 Ibid., 18.

14 Ibid., 6.

15 Bolívar Echeverría, La modernidad de lo barroco. Segunda edición, (México D.F.: Ediciones Era, 2000), 133.

16 Ibid., 138-139.
} 
Apropiándome de una reflexión de Manuel $\mathrm{Cruz}^{17}$ sobre la memoria, diría que la necesidad de recuperar nuestros momentos históricos y culturales es política, se trata de ir reconstituyendo enfoques que subyacen a nuestro ser profundo para ir solucionando nuestros problemas presentes.

\section{La Universidad y la cultura constitutiva latinoamericana}

Detrás de la modernidad liberal de América Latina se encuentra el fermento de una modernidad alternativa, de una racionalidad cuyo potencial se encuentra en nuestros primeros momentos de vida como sociedad. La mayoría de los problemas que enfrenta la región no son coyunturales sino más bien la expresión de una crisis estructural del sistema de legitimación.

El reconocimiento de la cuestionabilidad de la empresa conquistadora no debe eclipsar la experiencia histórica que significa el mestizaje y el origen de nuestras sociedades. Los primeros intelectuales que criticaron la empresa conquistadora desarrollaron argumentos que reflejaban la rica tradición intelectual del neoescolasticismo español. J. A. Fernández-Santamaría recuerda que este enfoque se asentaba en una noción de ley natural enriquecida por las tesis estoicas que enfatizaban nuestra humanidad común. ${ }^{18}$ Por su parte, Brian Tierney ha enfatizado el considerable fondo de jurisprudencia medieval que se encontraba en este cuerpo doctrinal. ${ }^{19}$ Francisco de Vitoria llega a desarrollar, según Tierney, una concepción moderna de los derechos que reconoce las dimensiones subjetivas de estos. ${ }^{20}$ Finalmente, este impresionante cuerpo doctrinal se enriquece a partir del humanismo cristiano que enfatiza un sentido profundo de espiritualidad y hermandad.

No es posible, por limitaciones de espacio, esbozar las influencias de este legado doctrinal en la generación del primer pensamiento latinoamericano. Luciano Pereña ${ }^{21}$ y Manuel Salord Beltrán ${ }^{22}$ han documentado el impresionante número de graduados de la Universidad de Salamanca -entonces uno

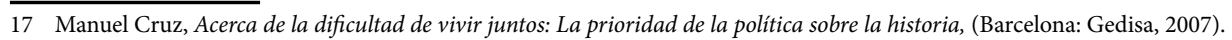

18 J. A. Fernández Santamaría, Natural Law, Constitutionalism, Reason of State and War. Counter Reformation Spanish Political Thought, Volume I, (New York: Peter Lang Publishing, 2005), 15.

19 Brian Tierney, The Idea of Natural Rights: Studies on Natural Rights, Natural Law, and Church Law 1150-1625, (Grand Rapids, Michigan: William B. Eerdmans Publishing Company, 1997).

20 Ibid., 258-259.

21 Luciano Pereña, La Escuela de Salamanca: Proceso a la conquista de América (Salamanca, Caja de Ahorros y Monte de Piedad de Salamanca, 1986), 216-256.

22 Manuel Ma. Salord Beltrán, La influencia de Francisco de Vitoria en el derecho indiano (México, D.F.: Porrúa, 2002), 528-553. 
de los focos críticos de la empresa de conquista- que vinieron a la América hispana a trabajar como profesores $\mathrm{u}$ oficiales reales.

Nuestras universidades se gestaron en un espíritu que no podía menos sino examinar con ojos críticos el proceso de conquista. Sin desconocer las limitaciones de dicho espíritu, impresiona el talante inquisitivo que lleva a comprender al Otro, en un contexto limitado por creencias religiosas estrictas. Se da una actitud de apertura hacia el Otro, siempre precaria y limitada por los propios prejuicios, pero que no podía sino sembrar las semillas de una nueva sociedad. Gerónimo Mendieta menciona explícitamente que Andrés de Olmos fue comisionado para estudiar la lengua y cultura náhuatl no solo para descubrir "lo malo", sino también para "que si algo bueno se hallase, se pudiese notar, cómo se notan y tienen en memoria muchas cosas de otros gentiles". ${ }^{23}$

Esta tradición de crítica a las estructuras injustas de la región latinoamericana se fue neutralizando sin desaparecer completamente. Reaparece, sin embargo, en momentos críticos de nuestra vida, como en algunas manifestaciones del espíritu independista y en movimientos intelectuales críticos como la filosofía de la liberación o la pedagogía crítica de la región. La constancia de una crítica que atraviesa siglos se ve atestiguada por las coincidencias que cualquier lector encuentra entre las obras de Bartolomé de las Casas y las páginas escritas por filósofos y teólogos de la liberación.

Es de subrayar que tal legado crítico, político y académico contribuyó a la supervivencia de la herencia de la cultura indígena. Detrás de la tarea destructora hubo una tarea de revitalización hecha posible por los indígenas mismos por medio de su colaboración con las primeras instituciones de enseñanza en América, tal es el caso del Colegio de Santa Cruz de Tlatelolco (fundado en 1536), cuyos estudiantes, dirigidos por Bernardino de Sahagún, nos heredaron textos que conservan los diversos aspectos de la cultura náhuatl. La empresa misionera quiso, en su momento, potenciar los elementos de las culturas aborígenes para hacer más efectiva su labor; en tal intento, la recuperación de dichas culturas no puede ser todo lo objetivo que quisiéramos. Pero es innegable la importancia del legado indígena, que

23 Citado en: Ascensión León Portilla y Miguel León-Portilla, Las primeras gramáticas del Nuevo Mundo (México, D.F.: Fondo de Cultura Económica, 2009), 27. 
no solo ha sobrevivido a partir de la mediación misionera sino también por medio de prácticas de resistencia.

Es de destacar, en este sentido, cómo las instituciones universitarias de la América hispana forman intelectuales conscientes de la riqueza de sus raíces indígenas y españolas. Juan de Palafox y Mendoza completa la constitución de la Real Universidad Mexicana al establecer que los indígenas deben ser aceptados como estudiantes. ${ }^{24}$ Es sintomático que Juan José de Eguiara y Eguren, quien fuera elevado a rector del centro de estudios en el que se formó, la Real Universidad de México, en su afán de demostrar, frente al prejuicio europeo la calidad de la cultura novohispana, haya empezado por poner de relieve los alcances de la cultura indígena, ${ }^{25}$ enfatizando el valor de la cultura mestiza, expresada en textos y libros que el ilustre profesor recopiló y comentó.

El caso de México no es aislado. José Mata Gavidia nos muestra la continuidad del legado de Palafox que se manifiesta en las constituciones de la Universidad de San Carlos. En efecto, estas estipulaban que los "indios (como vasallos libres de su Majestad), pueden ser admitidos a matrícula y grados". ${ }^{26}$ Esta universidad, creada siguiendo el modelo de la Universidad de Salamanca, con las diferencias que reflejan las condiciones de su gestación, ${ }^{27}$ establece junto a las cátedras de teología, derecho, medicina y filosofía, la Cátedra de lenguas indígenas. ${ }^{28} \mathrm{El}$ rector Francisco de Sassa y Arce, creador intelectual de la Universidad Carolina a juicio de Mata Gavidia, llega a establecer la enseñanza de las lenguas indígenas a nivel de facultad. ${ }^{29}$

Estas políticas de apertura académica llevaron a la creación de una actitud de fusión de diferentes tradiciones culturales. El especialista en historia de México, el británico David Brading ha puesto de relieve el hecho de la existencia de un indigenismo histórico. ${ }^{30}$ Este puede verse en la obra de los

24 Nancy H. Fee, "Biographical Essay", en Juan de Palafox y Mendoza, Virtues of the Indian/Virtudes del Indio. Editado y anotado por Nancy H. Fee, (Lahham, Maryland: Rowman \& Littlefield, 2009), 21.

25 Juan José de Eguiara y Eguren, Prólogos a la biblioteca Mexicana. Segunda edición en español, (México, D.F.: Fondo de Cultura Económica, 1984).

26 José Mata Gavidia, Fundación de la Universidad en Gutemala 1548-1688, (Ciudad de Guatemala: Editorial Universitaria, 1954), 111.

27 Por ejemplo, en la Universidad de San Carlos, los estudiantes eran excluidos del voto. Para Mata Gavidia, en general, los cambios introducidos eran "poco felices" respecto a la "formidable organización salmanticense". Véase el libro de José Mata Gavidia citado en la nota anterior, p. 98. Mata Gavidia también enfatiza que junto a la de Salamanca, se tomaron como modelos las universidades de Valladolidad y Alcalá.

28 Mata Gavidia, Fundación de la Universidad, cap. VII.

29 Ibid., 229.

30 David Brading, The Origins of Mexican Nationalism, (Cambridge: Cambridge University Press, 1985). 
creadores de la nacionalidad mexicana desde Alonso de la Veracruz hasta Fray Servando Teresa de Mier, pasando por Carlos de Sigüenza y Góngora y Xavier Clavijero. Estos intelectuales, a su vez, respondían a una tradición que incluía a intelectuales críticos como Alonso de Zorita, Vasco de Quiroga y Bernardino de Sahagún, los cuales habían generado una línea crítica respecto a la explotación de los indígenas, manteniendo el potencial benéfico que suponía la preservación de rasgos determinados de las culturas indígenas.

La postura crítica desarrollada por estos intelectuales tiene un marcado componente ético, ante todo, por el legado cristiano humanístico. Como lo recuerda el historiador mexicano Víctor Zavala, en la España del siglo XVI, los problemas humanos son visualizados desde la perspectiva de la conciencia. ${ }^{31}$ Esto introduce una serie de perspectivas críticas en las aulas universitarias de las primeras universidades latinoamericanas.

Desde luego, por su misma estructura y lineamientos ideológicos estas instituciones se resistieron a la penetración, en grados diferentes, de las ideas de la Ilustración. Las reformas borbónicas en México introdujeron las ideas ilustradas por medio de otras instituciones como el Jardín Botánico o el Real Seminario de Minas. ${ }^{32}$ Ellas ayudaron a regenerar el agotado pensamiento neoescolástico. Pero, a la vez, siguieron respetando el legado crítico que había sido generado por la cultura de nuestros países. En todo caso, no puede negarse que el pensamiento ilustrado significó con frecuencia la introducción de ideas negativas hacia la cultura hispanoamericana, especialmente en relación con una concepción discriminatoria hacia los indios. Estamos, en todo caso, frente a una historia accidentada y llena de matices, que no puede ser abordada en estas líneas.

Para concluir esta sección, puede afirmarse que los intelectuales, como los mencionados arriba, apuntan hacia algunos de los aspectos críticos de nuestros orígenes como conglomerados sociales. A partir de ellos, podemos encontrar senderos para revalorar las dimensiones histórico-culturales asociadas a nuestra injusticia estructural. El mestizaje profundo ofrece vetas cuya exploración está lejos de haber concluido. Recientemente, Ambrosio Velasco Gómez ha argumentado a favor de la relevancia del republicanismo multi-

31 Silvio Zavala, Por la senda hispana de la libertad. Segunda edición, (México, D.F.: Fondo de Cultura Económica, 1993 ), 15.

32 Renate Marsike, "Historia de la Universidad de México", Revista Historia de la Educación Latinoamericana 8 (2006): 16. 
cultural prefigurado por Las Casas y Alonso de la Veracruz para responder a los problemas actuales que plantea México. ${ }^{33}$

\section{El futuro de nuestras universidades}

Decía Ortega y Gasset que un "pueblo es un estilo de vida, y como tal, consiste en cierta modulación simple y diferencial que va organizando la materia en torno". ${ }^{34}$ Ortega pensaba que el fracaso e una colectividad era el fracaso de una sensibilidad intransferible que podía proyectar nuevas perspectivas, nuevas instituciones. Perder una cultura, por lo tanto, marca un empobrecimiento de las posibilidades humanas, más aún cuando las culturas en cuestión remiten a las corrientes constitutivas de un proyecto social que vino a ser lo que ahora somos.

El énfasis en las tradiciones, sin embargo, no debe vincularnos con ninguna perspectiva conservadora, mucho menos reaccionaria. Ante todo, porque lo que se busca es comprender lo que se es, para buscar lo que se puede ser. Luis Villoro, quien ha enfatizado el poder regenerador de las tradiciones que conforman una colectividad determinada, distingue entre naciones históricas y naciones proyectadas. La primera enfatiza el origen y una continuidad de rasgos culturales -una interpretación que no seguimos en estas páginas-. La segunda, en cambio, apuntala la conciencia de una herencia común que se realiza en la empresa de crear un nuevo proyecto. ${ }^{35}$

Las universidades latinoamericanas deben recuperar el pasado para proyectar soluciones orgánicas a nuestros problemas radicales. La vista puesta en el pasado es una reflexión que alumbra nuestra sensibilidad presente para descubrir posibilidades éticas para escapar de la actual crisis de legitimidad. Esto es necesario en sociedades como las nuestras, en las que el umbral moral se ha descolgado a partir de hábitos negativos que tienen que ser tematizados por nuestras reflexiones. ${ }^{36} \mathrm{La}$ tarea consiste en la creación de un ciudadano crítico que enfrenta su realidad de manera reflexiva, que comprende su pasado para encontrar su futuro.

\footnotetext{
33 Ambrosio Velasco Gómez, Republicanismo y multiculturalismo, (México, D.F.: Siglo XXI, 2006).

34 José Ortega y Gasset, Meditaciones del Quijote. Séptima edición, (Madrid: Cátedra, 2007), 171.

35 Luis Villoro, Estado Plural, Pluralidad de Culturas, (México, D.F.: Paidós, 1998), 16.

36 Los pensadores mexicanos Rodolfo Vázquez y Miguel Carbonell, por ejemplo, señalan, a propósito de la realidad mexicana (en un diagnóstico que puede ser extendido a las demás sociedades latinoamericanas), qué porcentajes importantes de la población consideran que es mejor "arreglarse" con las autoridades que cumplir con la ley. ¿No implica esto que la tarea de reforma social debe empezar al nivel de la conciencia personal? Véase Miguel Carbonell y Rodolfo Vázquez (eds.), Poder, derecho y corrupción (México, D.F.: Siglo XXI, 2003), 8.
} 
Esta simple tesis supone que todo proyecto que examine las raíces profundas de la crisis latinoamericana debe abrirse de manera radical a cuestionar ciertas instituciones comúnmente aceptadas en el ámbito de las democracias occidentales. Instituciones como el libre mercado o el sistema de partidos políticos necesitan ser readecuados en estos contextos sociohistóricos. Ahora bien, no se trata tan solo de poner al día las contribuciones del pasado, se trata, ante todo, de explorar nuevas sensibilidades, de proyectar nuevas maneras de ver el mundo y confrontarlas en su racionalidad intrínseca con otras visiones del mundo.

Este re-conocimiento se debe promover por medio de prácticas sociales, entre las cuales sobresale la educativa, una dimensión de la cual supone la colaboración de las universidades. Frente a siglos de indiferencia y de encubrimiento es necesario transformar la injusticia estructural que impide la humanización de las estructuras sociales latinoamericanas. Esta tarea supone una atención especial a una educación que ahora se propone el desarrollo de las auténticas capacidades morales del individuo, movilizando su sensibilidad para lograr el rechazo de la inhumanidad que se ha incrustado en el corazón de nuestras relaciones sociales.

Creo que la tarea descrita en estas páginas requiere proyectos de investigación concretos, cuya realización requiere marcos multidisciplinarios organizados dentro de nuestras universidades. Para brindar un ejemplo, uno de los proyectos que puede proponerse la universidad latinoamericana consiste en fortalecer la comunidad como una meta para romper el embrujo del autointerés que ha sido promovido por la cultura moderna capitalista. El sentido de comunidad de las tradiciones indígenas puede integrarse con el énfasis en la conciencia y el bien común que han sido heredados de la tradición católica. En la comunidad o en la sociedad que busca el bien común, el individuo se siente obligado o motivado a abrirse hacia el Otro en una responsabilidad cuyos límites no están marcados ni por el autointerés ni por el materialismo. La participación en los procesos de consolidación de la comunidad moviliza el sentido ético al levantar el umbral moral de la sociedad. Se necesitan repensar nuestros modelos de organización política y jurídica para promover el poder comunal y el local. Estos modelos de ejercicio político podrían llevar, con el tiempo, a paliar los problemas de la democracia representativa. 
En todo caso, lo anterior no significa dejar de lado las contribuciones del liberalismo en nuestro continente. Pero este debe adecuarse a las realidades de la región, y no debe seguir respondiendo a criterios que no son sensibles a los problemas de fondo de la realidad latinoamericana. En definitiva, el liberalismo nuestro se encuentra lejos del liberalismo anglosajón. La referencia al bien común, por ejemplo, nunca cede su espacio a la propia realización individual. Como lo recuerda Ortega -él mismo un liberalen sus Meditaciones del Quijote: "Yo soy yo y mi circunstancia; y si no la salvo a ella no me salvo yo" ${ }^{37}$ El nuestro es un sentido de libertad y compromiso que no puede independizarse de una tradición filosófica que siempre puso el énfasis en la conciencia que obliga a actuar al individuo en un aquí y ahora concretos.

Al mencionar esta recontextualización orgánica de liberalismo se puede recordar la figura del expresidente guatemalteco, el Dr. Juan José Arévalo, quien intentó fusionar instituciones socialistas y liberales en su "socialismo espiritual". El ejemplo de este presidente, el único pedagogo y filósofo que ha gobernado Guatemala, se manifiesta como una luz a seguir porque demuestra hasta qué punto la tradición intelectual hispanoamericana puede revitalizar la acción transformadora del paradigma de los derechos humanos. Arévalo cambia de manera profunda la fisonomía de uno de los países más desiguales de América Latina al acudir a un sentido de la justicia que se alimenta de su formación dentro de la tradición del krausismo español, ${ }^{38}$ que como lo ha notado José Luis Abellán, es junto con el humanismo erasmista, una de las manifestaciones del utopismo español. ${ }^{39}$ Así, el humanismo que caracterizó la primera crítica profunda de nuestras naciones se muestra como una posibilidad real para seguir pensado los problemas que agobian a América Latina.

\section{CONCLUSIÓN}

A las universidades latinoamericanas, pues, les corresponde, como una de sus misiones profundas, la reexaminación crítica de nuestras tradiciones in-

37 Ortega y Gasset, op. cit., 77.

38 Carlos Stoetzer, "Krausean philosophy as a Major Political and Social Force in the Modern Argentina and Guatemala," en Bridging the Atlantic: Towards a Reassessment of Iberian and Latin American Cultural Ties, editado por Marina Pérez de Mendieta (Albany, New York: State University of New York, 1996).

39 José Luis Abellán, "Introducción” en El krausismo y la Institución Libre de Enseñanza, editado por en A. García Jiménez (Madrid: Cincel, 1985), 14. 
telectuales y culturales para encontrar criterios para comprender nuestra injusticia estructural. Dicha tarea puede ayudarnos a romper la dependencia con respecto a modelos teóricos que, originados en otros contextos socioculturales, no pueden penetrar las raíces éticas de nuestras enormes carencias sociales. En nuestro peculiar mestizaje encontramos vetas amerindias e hispanas cuya elaboración teórica puede llevarnos a perspectivas más sensibles hacia los problemas concretos que afrontamos como naciones llagadas por la exclusión y la injusticia. La universidad latinoamericana puede ayudar a recuperar los senderos perdidos para construir un futuro más justo e incluyente para nuestras sociedades.

\section{REFERENCIAS}

Abellán, José Luis. “Introducción”. En El krausismo y la Institución Libre de Enseñanza, editado por A. Jiménez García, 11-17, Madrid: Cincel, 1985.

Brading, David. The Origins of Mexican Nationalism. Cambridge: Cambridge University Press, 1985.

Carbonell, Miguel y Rodolfo Vázquez. Poder, derecho y corrupción. México, D. F.: Siglo XXI, 2003.

Cruz, Manuel. Acerca de la dificultad de vivir juntos: La prioridad de la politica sobre la historia. Barcelona: Gedisa, 2007.

Drake, Paul W. Between Tyranny and Anarchy: A History of Democracy in Latin America, 18002006. Stanford: Stanford University Press, 2009.

Desmond Arias, Enrique y Daniel M. Goldstein. Violent Democracies of Latin America, Durham NC: Duke University Press, 2010.

Echeverría, Bolívar. La modernidad de lo barroco. $2^{a}$ ed. México D.F.: Ediciones Era, 2010.

Eguiara y Eguren, Juan José. Prólogos a la biblioteca mexicana. $2^{a}$ ed. en español. México, D. F.: Fondo de Cultura Económica, 1984.

Fee, Nancy H. "Biographical Essay". En Virtues of the Indian/Virtudes del Indio. Libro de Juan de Palafox y Mendoza, editado y anotado por Nancy H. Fee. Lahham. Maryland: Rowman \& Littlefield, 2009.

Fernández Santamaría, J. A. Natural Law, Constitutionalism, Reason of State and War. Counter Reformation Spanish Political Thought, Volume I. New York: Peter Lang Publishing, 2005

Hoyos Vásquez, Guillermo. “Filosofía latinoamericana significa uso ético de la razón práctica". Isegoría 19 (1998): 79-96.

León-Portilla, Ascensión y Miguel León Portilla. Las primeras gramáticas del Nuevo Mundo. México, D. F.: Fondo de Cultura Económica, 2009. 
Levinas, Emmanuel. Totalidad e infinito: Ensayo sobre la exterioridad. Traducción de Daniel Guillot. Salamanca: Sígueme, 2006.

Marsike, Renate. “Historia de la Universidad de México” RHELA 8 (2006): 9-34.

Mata Gavidia, José. Fundación de la Universidad en Guatemala 1548-1688. Ciudad de Guatemala: Editorial Universitaria, 1954.

Ortega y Gasset, José. Meditaciones del Quijote. $7^{a}$ ed. Madrid: Cátedra, 2007.

Pereña, Luciano. La Escuela de Salamanca: Proceso a la conquista de América. Salamanca: Caja de Ahorros y Monte de Piedad de Salamanca, 1986.

Rawls, John. A Theory of Justice. Cambridge, Massachusetts: Harvard University Press, 1999.

Salord Beltrán, Manuel Ma. La influencia de Francisco de Vitoria en el derecho indiano. México, D. F.: Porrúa, 2002.

Stoetzer, Carlos. (1996): "Krausean philosophy as a Major Political and Social Force in the Modern Argentina and Guatemala". En Bridging the Atlantic: Towards a Reassessment of Iberian and Latin American Cultural Ties, editado por Marina Pérez de Mendieta, 83-105, New York: State University of New York Press.

Tierney, Brian. The Idea of Natural Rights: Studies on Natural Rights, Natural Law, and Church Law 1150-1625. Grand Rapids, Michigan: William B. Eerdmans Publishing Company, 1997.

United Nations Development Programme. Democracy in Latin America: Towards a Citizen's Democracy. New York: United Nations Development Programme, 2004.

Velasco Gómez, Ambrosio. Republicanismo y multiculturalismo. México, D. F.: Siglo XXI, 2006.

Villoro, Luis. Estado Plural, Pluralidad de Culturas. México, D. F.: Paidós, 1998.

Villoro, Luis. Tres retos de la sociedad por venir: Justicia, Democracia, Pluralidad. México, D. F.: Siglo XXI, 2009.

Young, Iris Marion. Political Responsibility and Structural Injustice. Kansas City: Departamento de Filosofía, Universidad de Kansas, 2001.

Zavala, Silvio. Por la senda hispana de la libertad. Segunda edición. México, D. F.: Fondo de Cultura Económica, 1993.

\begin{tabular}{|l|}
\hline Rodríguez-Martínez, Jorge Mario, "La universidad latinoamericana como \\
recuperación y futuro". Revista Historia de la Educación Latinoamericana. \\
Vol. $16 \mathrm{No}, 22,(2014): 19$ - 34.
\end{tabular}

